\title{
eGFR values and selected renal urine biomarkers in preterm neonates with uncomplicated clinical course
}

\author{
Monika Miklaszewska1,A-D, Przemysław Korohoda 2, ${ }^{2,-E}$, Dorota Drożdż',E,F, Katarzyna Zachwieja 1,B,E, \\ Tomasz Tomasik ${ }^{3, B}$, Anna Moczulska ${ }^{1, B}$, Agata Korzeniecka-Kozerska ${ }^{4, C}$, , Przemko Kwinta ${ }^{3, B-F}$ \\ 1 Department of Pediatric Nephrology and Hypertension, Jagiellonian University Medical College, Kraków, Poland \\ 2 Department of Electronics, Faculty of Computer Science, Electronics and Telecommunications, AGH University of Science and Technology, Kraków, Poland \\ ${ }^{3}$ Department of Pediatrics, Faculty of Medicine, Jagiellonian University Medical College, Kraków, Poland \\ ${ }^{4}$ Department of Pediatrics and Nephrology, Medical University of Białystok, Poland \\ A - research concept and design; B - collection and/or assembly of data; C - data analysis and interpretation; \\ $D$ - writing the article; $E$ - critical revision of the article; $F$ - final approval of the article
}

\section{Address for correspondence}

Monika Miklaszewska

mmiklasz@wp.pl

Funding sources

This work was supported by the Research Project Grant No. NN 407459738.

\section{Conflict of interest}

None declared

Received on August 13, 2018

Reviewed on January 28, 2019

Accepted on June 27, 2019

Published online on December 17, 2019

Cite as

Miklaszewska M, Korohoda P, Drożdż D, et al. eGFR values and selected renal urine biomarkers in preterm neonates with uncomplicated clinical course. Adv Clin Exp Med. 2019:28(12):1657-1666. doi:10.17219/acem/110317

DOI

10.17219/acem/110317

\section{Copyright}

Copyright by Author(s)

This is an article distributed under the terms of the

Creative Commons Attribution 3.0 Unported (CC BY 3.0)

(https://creativecommons.org/licenses/by/3.0/)

\begin{abstract}
Background. Diagnosing acute kidney injury (AKI) in preterm newborns, who are particularly susceptible to renal damage, is a serious challenge as there is no definite consensus about the diagnostic criteria.

Objectives. The objective of this study was to measure the values for selected urinary biomarkers and estimated glomerular filtration rate (eGFR) among a population of preterm infants with uncomplicated clinical course as well as to determine whether these markers depend on birth weight (BW), gestational age (GA), postnatal age (PNA), or gender.
\end{abstract}

Material and methods. The prospective study was carried out in neonatal intensive care unit (NICU). The evaluation included 57 children that were divided into 3 categories according to BW: low birth weight (LBW) - 1501-2500 g (22 infants); very low birth weight (VLBW) - 1000-1500 g (25 infants); and extremely low birth weight (ELBW) - 750-999 g (10 infants). Urine samples were collected daily between the $4^{\text {th }}$ and $28^{\text {th }}$ day of life for measurements of creatinine ( $\mathrm{Cr}$ ), neutrophil gelatinase-associated lipocalin (NGAL), osteopontin (OPN), and human kidney injury molecule 1 (hKIM1).

Results. The values of the 3 urine tubular biomarkers, serum creatinine and eGFR were taken in substantially healthy preterm infants with normal kidney function at 4 time intervals during the neonatal period. Their correlations were determined and a multivariable regression analysis was carried out with respect to BW, GA, PNA, and gender. Trends of the studied markers in terms of PNA and BW were also assessed with the Jonckheere-Terpstra test.

Conclusions. Glomerular and tubular function in preterm neonates during the $1^{\text {st }}$ month of life is significantly influenced by BW, GA, PNA, and gender.

Key words: renal function, renal urine biomarkers, premature neonate 


\section{Introduction}

Worldwide, approx. 6-10\% of infants are born preterm. Preterm neonates are particularly susceptible to renal damage, as they are born before week 36 of gestation, when the complex process of nephrogenesis is still incomplete. ${ }^{1,2}$

Diagnosing acute kidney injury (AKI) in preterm newborns is a serious challenge because there is no definite consensus about the diagnostic criteria. Its true incidence among this age group is actually unknown, but the risk for this complication is considerably higher in more immature neonates. ${ }^{3,4}$ Generally, AKI occurs in as many as $56 \%$ of neonates treated in neonatal intensive care units (NICU), ${ }^{5}$ while the mortality rate among this population with AKI ranges from $33 \%$ to $78 \%{ }^{6}$

The search for new AKI markers is based on the poor prognosis of AKI in newborns, which is partially caused by the delay in diagnosis and therapeutic intervention. Diagnosis made only on the basis of serum creatinine ( $\mathrm{SCr}$ ) level in this specific population is made more complicated by several factors, including birth weight (BW), gestational (GA) and postnatal age (PNA), functional tubular immaturity, low glomerular filtration rate (GFR), high renal vascular resistance, high plasma renin activity, and decreased intercortical perfusion. ${ }^{7,8}$ Furthermore, $\mathrm{SCr}$ is a measure of glomerular function - not of kidney damage. ${ }^{9}$

Advances in the field of clinical proteomics have greatly accelerated the discovery of novel urinary proteins which promptly increase in response to renal tubular injury. ${ }^{10}$ Urine AKI biomarkers include neutrophil gelatinase-associated lipocalin (NGAL), ${ }^{11}$ human kidney injury molecule 1 (hKIM1) ${ }^{12,13}$ and osteopontin (OPN), ${ }^{14}$ among many others. Plasma NGAL is freely filtered by the glomerulus and then largely reabsorbed by proximal tubular cells captured by megalin; thus, very little $(0.1-0.2 \%)$ is found in the urine. ${ }^{15}$ With renal tubular injury, NGAL reabsorption may be decreased, whereas its de novo synthesis in the epithelial cells of the loop of Henle and of distal tubule segments is strongly upregulated, after which it is found in high concentrations in the urine. ${ }^{16}$ Neutrophil gelatinase-associated lipocalin has also been shown to play an important role in kidney development. ${ }^{17}$ Osteopontin in the kidney is mainly found in the loop of Henle and distal nephrons, can be upregulated in all tubular and glomerular segments following kidney damage and may play a role in renal repair. ${ }^{18}$ Human kidney injury molecule 1 is expressed in low levels in healthy proximal tubule cells; in case of kidney ischemia or toxicity, it is highly upregulated and shed into the extracellular space and the urine. ${ }^{19}$

According to the literature, these biomarkers are not only more sensitive than SCr for identifying AKI, but they can also indicate damage in a specific tubular region of the nephron. ${ }^{20}$ Additionally, the ability to assay the markers noninvasively in the urine represents a significant advantage over current methods, especially for the neonatal population. ${ }^{21}$ Still, despite the promising role of these novel urinary biomarkers in the early detection of AKI, a reference range for the preterm neonatal population has not yet been fully established. The inability of immature tubules to fully reabsorb these proteins in preterm infants may also lead to varying values in this heterogenic population. ${ }^{8}$ Hence, the primary objective of this study was to determine the values for selected urinary tubular biomarkers in a population of preterm infants who have relatively uncomplicated clinical courses, and to determine whether these markers depend on BW, GA, PNA, or gender. To evaluate and characterize the glomerular function of the studied group, the estimated GFR (eGFR) values were calculated with the equation developed by Schwartz et al., ${ }^{22}$ which is easy to use bedside.

\section{Material and methods}

The prospective, observational study was carried out in the Neonatal Intensive Care Unit of the Department of Pediatrics at Jagiellonian University College of Medicine in Kraków, Poland. Prospective observations spanned the period from September 2010 to September 2012. The investigation was approved by the local Bioethical Committee (approval No. KBET/64/B/2009).

The inclusion criteria were as follows: informed consent of the parents (or legal guardians) and an age of up to $48 \mathrm{~h}$ upon the child's admission to the NICU. Ultimately, in the final analysis of data, only NICU survivors were included. The exclusion criteria consisted of a lack of informed consent, prenatal maternal angiotensin-converting enzyme (ACE) inhibitor or indomethacin therapy, congenital anomalies of the kidney and urinary tract (CAKUT), chromosomal aberrations, other severe, complex anomalies affecting an unfavorable late prognosis and complications such as acute renal failure, sepsis, suspicion of sepsis, urinary tract infection, tension pneumothorax, necrotizing enterocolitis, grade 3 and 4 intracranial hemorrhage, patent ductus arteriosus (PDA) requiring treatment, therapy with nonsteroidal anti-inflammatory drugs or amphotericin, or any type of surgery during the entire observation period.

The presence of AKI in a given child was determined based on the neonatal/pediatric (n/p) RIFLE and AKIN scales. ${ }^{5,23}$ Serum creatinine was assessed at least every 48-72 $\mathrm{h}$ and whenever it seemed necessary. The normal ranges of $\mathrm{SCr}$ used for the studied population were taken from the study of Bateman et al. ${ }^{24}$, while the eGFR values were calculated according to the one-marker equation developed by Schwartz et al. ${ }^{22}$ The presence of sepsis in a given child was determined based on the gold standard, which continues to be a positive result of blood bacteriology, while a suspicion of sepsis was based on such clinical and laboratory criteria as apnea or deterioration of mechanical ventilation parameters, abnormalities of peripheral perfusion, abnormalities of arterial pressure, hepatomegaly and/ 
or splenomegaly, signs of feeding intolerance, leucopenia $(<4,000 / \mathrm{mL})$ or elevated white blood cell count $(>10,000 / \mathrm{mL})$, thrombocytopenia $(<100,000 / \mathrm{mL})$, immature granulocyte count (immature neutrophils/total neutrophils) $>0.2$, and elevated C-reactive protein (CRP) (>10 mg/L).

In the calculation process of the final results for urinary markers, only data from days without aminoglicoside (AG) administration, injury or $2^{\text {nd }}$ stage of AKI according to the $\mathrm{n} / \mathrm{pRIFLE}$ and AKIN scale, respectively, or signs or symptoms of sepsis were taken into consideration. The only AG used in our NICU was amikacin. The antibiotic was dosed under close serum level monitoring. Respiratory failure (RF) was recognized when the implementation of synchronized intermittent mandatory ventilation (SIMV) or continuous positive airway pressure (CPAP) was warranted. Nevertheless, in view of the fact that very low birth weight (VLBW) and extremely low birth weight (ELBW) children very often require respiratory support, either SIMV or CPAP, it was not considered an exclusion criterion.

Clinical observations were performed over the first 28 days of life (DOL). Urinary concentrations of the markers being studied were measured on a daily basis between the $4^{\text {th }}$ and $28^{\text {th }}$ DOL (25 days). A urine sample for creatinine (uCr), NGAL (uNGAL), OPN (uOPN), and hKIM1 assays was collected according to the schedule, once a day (at 7.00 a.m.) using a urine bag or a catheter. None of the children were specially catheterized to meet the purpose of the investigation; the insertion of a urinary catheter was dictated by the clinical status of the child. In order to obtain an appropriate volume of urine, in the case of catheterized children, the urine bags were emptied approx. $1 \mathrm{~h}$ prior to the planned urine collection, while in case of children without urinary catheters, a urine bag was fixed approx. $1 \mathrm{~h}$ before the planned urine collection. The values of the markers were analyzed in 4 time intervals: $4-7,8-14,15-21$, and 22-28 DOL.

\section{Description of laboratory methods}

The collected urine was centrifuged and frozen at $-80^{\circ} \mathrm{C}$. Laboratory measurements of $\mathrm{SCr}$ and $\mathrm{uCr}$ were performed using the enzymatic method with a VITROS FS system (Ortho Clinical Diagnostics, Raritan, USA). The reading and recording of the results were automatic. The methods of analysis remained unchanged throughout the study period. Measurements of NGAL were performed employing a Human Lipocalin - 2/NGAL ELISA RD 191102200R kit (BioVendor, Brno, Czech Republic) and the immunoenzymatic method (enzyme-linked immunosorbent assay (ELISA)). The kit had the following parameters: intra-kit precision $\mathrm{CV}-7.7 \%$; inter-kit precision $\mathrm{CV}-9.8 \%$; and sensitivity of the method $-<0.02 \mathrm{ng} / \mathrm{mL}$. Determination of OPN was carried out using the Human Osteopontin Elisa BBT0482R kit (BioVendor) and the immunoenzymatic method (ELISA). The kit had the following parameters: intra-kit method precision $\mathrm{CV}-3.7 \%$; inter-kit precision $\mathrm{CV}$
$-5.8 \%$; sensitivity of the method $-<50 \mathrm{pg} / \mathrm{mL}$; measurement range $-156-10,000 \mathrm{pg} / \mathrm{mL}$. Measurements of human Kidney Injury Molecule-1 (hKIM1) were performed with an Elisa Kit for Human Kidney Injury Molecule 1 (Kim1) E0785HU kit (USCN Life Science Inc., Wuhan, China) and the immunoenzymatic method (ELISA). The kit had the following parameters: intra-kit method precision CV $-<10 \%$; inter-kit precision $\mathrm{CV}-<12 \%$; sensitivity of the method - $<0.038 \mathrm{ng} / \mathrm{mL}$; and measurement range $-0.156-$ $10 \mathrm{ng} / \mathrm{mL}$. Sample absorbance was measured by the single-wave method using a 450-nm filter and the Universal Microplate Reader Elx800NB automatic microplate reader (BIO-TEK Instruments, Inc, Winooski, USA). Correction of urinary biomarker measurements with urine creatinine was performed to account for urine concentration.

\section{Predefined comparisons}

The children were divided into 3 categories according to their BW: low birth weight (LBW) infants with a BW of 1,501-2,500 g; VLBW infants with a BW of 1,0001,500 g; and ELBW infants with a BW of 750-999 g.

\section{Statistical methods}

The following tests were used, as deemed appropriate: Kolmogorov-Smirnov test (KS), Student's t-test, rank sum Wilcoxon test, and Fisher's exact test. For normally distributed variables, the mean and standard deviation (SD) were calculated; otherwise, the median and interquartile range (IQR) range are presented. The significance level was 0.05 for all tests, apart from the KS test, where it was set to 0.1 in order to make it more restrictive for the null hypothesis. The values of the studied markers were preliminarily calculated by the common logarithm, as in the papers listed in References $^{10,17,25}$; zero values - accounting for $10.8 \%$ of the results - were rejected. In this way, the log-norm distribution was achieved for all of the groups, as confirmed by the KS test. Having determined the parameters of the Gaussian model for the log-norm data, the authors defined 50\% confidence intervals (CI50\%), which - in the case of a Gaussian distribution - are equivalent to IQR. Subsequently, the mean values of the log-norm distributions and the CI50\% range limits were converted to original values of the markers, thus arriving at respective geometric means and CI50\% range limits. Statistical comparisons of data groups analyzed in this way were performed using Student's t-test for the logarithmic values. For the above values of the markers, the authors analyzed possible correlations with BBW, GA and DOL, also grouping by gender, and carried out a multivariable regression analysis in order to determine their dependence on the abovementioned variables. The Jonckheere-Terpstra test, a rank-based nonparametric test, was used to determine if there is a statistically significant trend between the ordinal independent variables (calendar-day intervals (4-7, 8-14, 15-21 and 22-28 DOL) and BW groups (ELBW, 
VLBW and $L B W)$ ) and the continuous dependent variables: eGFR, SCr, uNGAL, uOPN, and hKIM1 concentrations. The STATISTICA v. 12.0 (StatSoft, Inc., Tulsa, USA) and MATLAB v. 2015a (Mathworks, Natick, USA) packages were used for all computations and to create the graphs.

\section{Results}

Fifty-seven infants were included in the study: 22 LBW, 25 VLBW and 10 ELBW newborns. All of the infants were of Caucasian race. The main diagnoses at admission in the LBW group were respiratory disorders (of various severity and origin) ( $n=14)$ and prematurity $(n=8)$; in the VLBW group, it was respiratory disorders (of various severity and origin) $(n=6)$ and prematurity and severe prematurity $(n=19)$; and in the ELBW group, the diagnosis was severe prematurity with respiratory disorders $(n=10)$. None of the children enrolled in the study died during their NICU stay.

As shown in Table 1, which presents a clinical summary of the investigated population, the analyzed groups of children were comparable with respect to gender, delivery methods, fetal maturity, Apgar score, urine output (UO), and AG use. The infants from all study groups were generally in a good and stable condition throughout the entire observation period, as confirmed by their Score for Neonatal

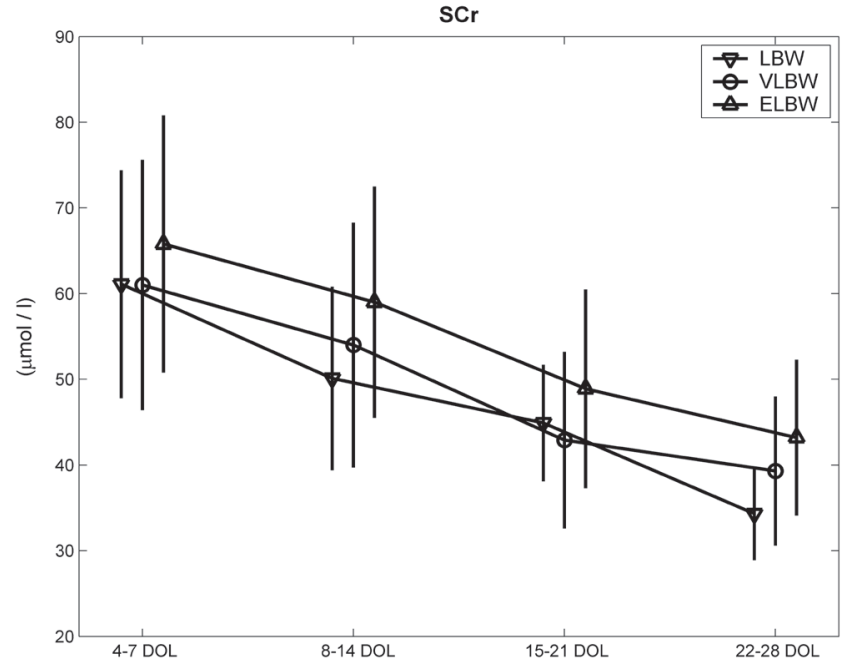

Fig. 1. Serum creatinine distribution parameters: mean $\pm S D$, calculated from data collected in 4 weekly intervals in the study population

Acute Physiology II (SNAP II), which practically did not exceed the mean value of 5 points in any of the analyzed subgroups (a fact which predicts a good prognosis in a neonate) and showed no significant differences among the subgroups. ${ }^{26}$ Similarly, the mean arterial pressure (MAP) values of the studied patient populations were within normal limits for their GA, at approx. the $50^{\text {th }}$ percentile. ${ }^{27}$

Table 1. Clinical summary of the study population $(n=57)$

\begin{tabular}{|c|c|c|c|c|c|c|}
\hline Variable & $\operatorname{LBW}(n=22)$ & $\operatorname{VLBW}(\mathrm{n}=25)$ & $\operatorname{ELBW}(n=10)$ & $\begin{array}{c}p \text {-value } \\
(\text { LBW vs VLBW) }\end{array}$ & $\begin{array}{c}\text { p-value } \\
\text { (LBW vs ELBW) }\end{array}$ & $\begin{array}{c}p \text {-value } \\
\text { (VLBW vs ELBW) }\end{array}$ \\
\hline & Number (\%) & Number (\%) & Number (\%) & \multicolumn{3}{|c|}{$p$-value for Fisher's exact test } \\
\hline Females/males & $10(45 \%) / 12(55 \%)$ & 15 (60\%)/10 (40\%) & 5 (50\%)/5 (50\%) & NS & NS & NS \\
\hline Cesarean delivery & 20 (91\%) & $19(76 \%)$ & $10(100 \%)$ & NS & NS & NS \\
\hline SGA/AGA & $3(14 \%)$ & $1(4 \%)$ & $1(10 \%)$ & NS & NS & NS \\
\hline PDA & $7(31.8 \%)$ & $8(32 \%)$ & $4(40 \%)$ & NS & NS & NS \\
\hline RF & $11(50 \%)$ & $19(76 \%)$ & $9(90 \%)$ & NS & 0.0469 & NS \\
\hline \multirow[t]{2}{*}{$A G$} & $2(9.1 \%)$ & $8(32 \%)$ & $2(20 \%)$ & NS & NS & NS \\
\hline & Mean (SD) & Mean (SD) & Mean (SD) & \multicolumn{3}{|c|}{$\mathrm{p}$-value for Student t-test } \\
\hline GA [weeks] & $32.4(2.1)$ & $29.2(1.7)$ & $28.0(2.4)$ & 0.000 & 0.000 & NS \\
\hline BW [g] & $1710.2(166.2)$ & $1244.8(161.0)$ & 947.5 (53.8) & 0.000 & 0.000 & 0.000 \\
\hline \multirow[t]{2}{*}{ Birth body length [cm] } & $43.4(1.9)$ & $38.9(2.5)$ & $36.6(1.6)$ & 0.000 & 0.000 & 0.011 \\
\hline & Median (IQR) & Median (IQR) & Median (IQR) & \multicolumn{3}{|c|}{$p$-value for Wilcoxon test } \\
\hline Apgar score $3 / 5$ & $8(2.0)$ & $7(4.0)$ & $6.5(2.0)$ & NS & NS & NS \\
\hline SNAP \| & $5.0(0.0)$ & $5.0(0.0)$ & $5.0(5.0)$ & NS & NS & NS \\
\hline RF - number of days & $2.0(5.3)$ & $4.0(17.3)$ & $24.0(4.3)$ & NS & 0.000 & 0.015 \\
\hline $\mathrm{MAP}[\mathrm{mm} \mathrm{Hg}]$ & $49.7(13.0)$ & $46.0(12.3)$ & $44.3(12.3)$ & 0.000 & 0.000 & 0.008 \\
\hline $\begin{array}{l}\text { AG administration } \\
\text { - number of days }\end{array}$ & $4.0(2.0)$ & $4.5(4.00)$ & & NS & NS & NS \\
\hline $\mathrm{UO}[\mathrm{mL} / \mathrm{kg} / \mathrm{h}]$ & $2.9(0.9)$ & $3.1(1.0)$ & $2.9(1.3)$ & NS & NS & NS \\
\hline NICU hospitalization [days] & $27.5(16.0)$ & $45.0(24.8)$ & $63.0(21.0)$ & 0.000 & 0.000 & NS \\
\hline
\end{tabular}

RF - respiratory failure (number of days of CPAP and SIMV administration); AG - number of days of AG administration within the group that received an antibiotic; SL - spontaneous labor; CS - cesarean section; MAP - mean arterial pressure; UO - urinary output; SGA - small for gestational age; AGA - appropriate for gestational age; BW - body weight; LBW - low body weight; VLBW - very low body weight; ELBW - extremely low body weight; NICU - neonatal intensive care unit; SD - standard deviation. 
Table 2. Serum creatinine $(\mathrm{SCr})$ and estimated glomerular filtration rate (eGFR) distribution parameters calculated from data collected in 4 weekly intervals in the studied population; data is presented as mean (standard deviation (SD)); $p$-values were computed for the Jonckheere-Terpstra test for ordered alternatives

\begin{tabular}{|c|c|c|c|c|c|}
\hline Variable & $\begin{array}{l}4-7 \\
\text { DOL }\end{array}$ & $\begin{array}{l}8-14 \\
\text { DOL }\end{array}$ & $\begin{array}{c}15-21 \\
\text { DOL }\end{array}$ & $\begin{array}{c}22-28 \\
\mathrm{DOL}\end{array}$ & p-value \\
\hline \multicolumn{6}{|c|}{$\mathrm{SCr}[\mu \mathrm{mol} / \mathrm{L}]$} \\
\hline LBW & $61.1(13.3)$ & $50.1(10.7)$ & $44.9(6.8)$ & $34.3(5.4)$ & 0.000 \\
\hline VLBW & $61.0(14.6)$ & $54.0(14.3)$ & $42.9(10.3)$ & $39.3(8.7)$ & 0.01 \\
\hline ELBW & $65.8(15.0)$ & $59.0(13.5)$ & 48.9 (11.6) & $43.2(9.1)$ & 0.02 \\
\hline$p$-value & 0.05 & 0.03 & NS & 0.01 & \\
\hline \multicolumn{6}{|c|}{$\mathrm{eGFR}\left[\mathrm{mL} / \mathrm{min} / 1.73 \mathrm{~m}^{2}\right]$} \\
\hline LBW & $27.4(7.1)$ & $33.9(9.70)$ & $36.8(5.3)$ & $48.2(7.9)$ & 0.000 \\
\hline VLBW & $24.6(5.5)$ & $28.4(7.1)$ & $36.4(9.6)$ & $39.6(9.2)$ & 0.003 \\
\hline ELBW & $21.3(6.1)$ & $24.7(7.9)$ & $29.8(8.9)$ & $33.9(9.7)$ & 0.03 \\
\hline p-value & 0.01 & 0.02 & 0.05 & 0.005 & \\
\hline
\end{tabular}

DOL - days of life; LBW - low body weight; VLBW - very low body weight; ELBW - extremely low body weight.

The number of days when a urine sample could potentially be collected was as follows: in the LBW group - 429; in the VLBW group - 623; and in the ELBW group - 251 (in total: 1,303 days). The final number of days included

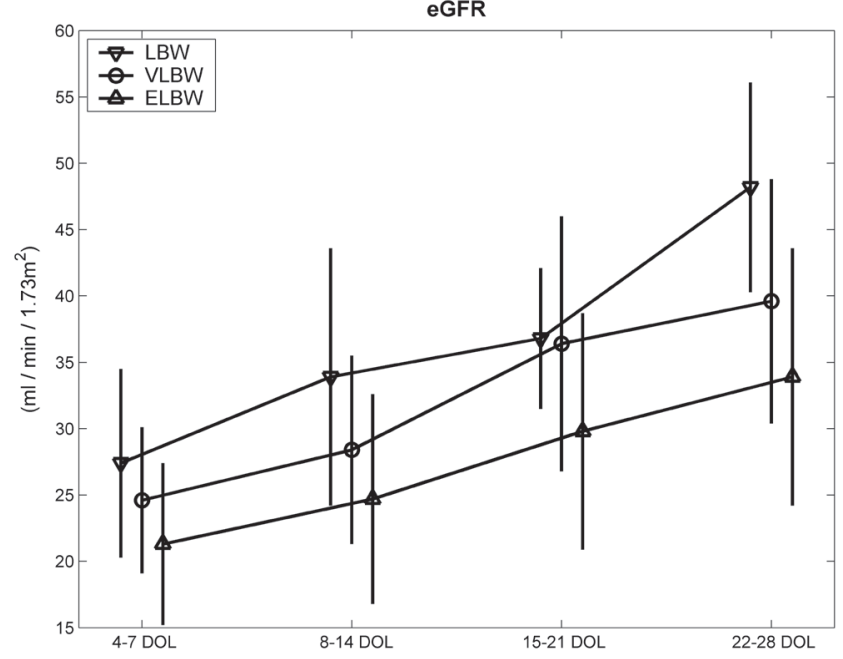

Fig. 2. Estimated glomerular filtration rate (eGFR) distribution parameters: mean $\pm S D$, calculated from data collected in 4 weekly intervals in the study population

in the analysis - once days affected by the above interfering factors were excluded - was 1,126 (86.4\%), with the following values for the selected population groups: LBW - 374 (87.2\%), VLBW - 538 (86.4\%) and ELBW - 214 (85.3\%).

Table 3. Geometric mean and Cl50\% of uNGAL values calculated from data collected in 4 weekly intervals in the study groups; p-values were computed for the Jonckheere-Terpstra test for ordered alternatives

\begin{tabular}{|c|c|c|c|c|c|}
\hline Variable & 4-7 DOL & 8-14 DOL & 15-21 DOL & $22-28 \mathrm{DOL}$ & $\mathrm{p}$-value \\
\hline \multicolumn{6}{|c|}{ Females } \\
\hline \multicolumn{6}{|c|}{$\mathrm{NGAL}[\mathrm{ng} / \mathrm{mL}]$} \\
\hline LBW & $11.1(4.7-25.9)$ & $6.7(2.9-15.5)$ & $4.7(1.6-14.3)$ & $15.8(6.7-37.0)$ & NS \\
\hline VLBW & $24.0(10.2-56.6)$ & $14.3(5.1-40.2)$ & $11.2(4.2-29.8)$ & $9.4(4.1-21.7)$ & $<0.001$ \\
\hline ELBW & $19.3(8.9-41.9)$ & $15.2(7.1-32.5)$ & $12.4(6.9-22.3)$ & $18.5912 .5-27.3)$ & NS \\
\hline p-value & 0.02 & 0.01 & 0.02 & NS & - \\
\hline \multicolumn{6}{|c|}{$\mathrm{NGAL}[\mathrm{ng} / \mathrm{mgCr}]$} \\
\hline LBW & 69.7 (33.0-147.2) & 46.9 (20.4-107.8) & $36.8(11.1-122.4)$ & 120.7 (52.6-276.8) & NS \\
\hline VLBW & $217.1(89.9-524.2)$ & $120.0(40.4-356.3)$ & $89.4(32.2-247.6)$ & 78.7 (30.9-200.6) & $<0.001$ \\
\hline ELBW & $173.3(62.9-477.4)$ & 116.7 (44.3-307.6) & $94.0(46.8-188.8)$ & $155.4(83.9-287.8)$ & NS \\
\hline p-value & 0.05 & 0.03 & 0.01 & NS & - \\
\hline \multicolumn{6}{|c|}{ Males } \\
\hline \multicolumn{6}{|c|}{$\mathrm{NGAL}[\mathrm{ng} / \mathrm{mL}]$} \\
\hline LBW & $5.5(2.3-13.10)$ & $3.1(1.2-8.0)$ & $3.3(1.1-10.1)$ & $1.8(0.9-3.5)$ & 0.01 \\
\hline VLBW & $14.7(6.3-34.3)$ & $9.0(2.5-32.0)$ & $5.8(1.7-19.2)$ & $3.9(1.1-14.2)$ & $<0.001$ \\
\hline ELBW & $23.0(12.0-44.0)$ & $23.6(8.2-67.7)$ & $8.7(3.4-21.7)$ & $7.5(2.9-19.7)$ & 0.03 \\
\hline$p$-value & $<0.001$ & $<0.001$ & 0.02 & 0.01 & - \\
\hline \multicolumn{6}{|c|}{$\mathrm{NGAL}[\mathrm{ng} / \mathrm{mgCr}]$} \\
\hline LBW & 36.8 (15.4-87.8) & $22.3(8.3-59.9)$ & $22.6(7.7-66.8)$ & $9.7(4.6-20.4)$ & 0.01 \\
\hline VLBW & 110.7 (45.0-272.2) & $81.2(23.9-276.1)$ & $51.0(15.3-170.1)$ & $33.1(9.6-114.2)$ & $<0.001$ \\
\hline ELBW & $208.6(113.3-384.0)$ & $172.7(60.3-494.1)$ & 78.1 (33.5-182.3) & $65.4(25.6-166.9)$ & 0.02 \\
\hline$p$-value & $<0.001$ & $<0.001$ & 0.01 & 0.003 & - \\
\hline
\end{tabular}

DOL - days of life; LBW - low body weight; VLBW - very low body weight; ELBW - extremely low body weight; NGAL - neutrophil gelatinase-associated lipocalin; UNGAL - urine neutrophil gelatinase-associated lipocalin. 
Table 2 and Fig. 1 and 2 present the values of SCr and eGFR calculated for the study groups. As it follows from the data and the Jonckheere-Terpstra test results for ordered alternatives, there is a statistically significant trend of lower SCr values and higher eGFR values in all BW groups with respect to PNA; simultaneously, there is a significant trend of higher SCr values and lower eGFR values with respect to lower BW (except for $\mathrm{SCr}$ values in the $3^{\text {rd }}$ time interval).

Table 3 presents the geometric means and CI50\% for the values of $\mathrm{UNGAL}$, separated by gender, that were found in the 4 time intervals in the groups of children. As it follows from the data and the Jonckheere-Terpstra test results for ordered alternatives, there is a statistically significant trend of lower uNGAL values with respect to PNA (except LBW and ELBW females); likewise, there is a significant trend of higher uNGAL values with respect to lower BW (except for females in the $4^{\text {th }}$ time interval). The analysis of logarithmic correlations of the UNGAL values performed both in girls and in boys demonstrated negative, average and high coefficients (R: $-0.4--0.7$; Table 6) for all of the UNGAL values, with respect to both BW and GA. Similarly, the analysis of the results of the multivariable linear regression for logarithmic UNGAL values with respect to BW, GA, PNA, and gender demonstrated a significant effect from all of these factors on the UNGAL values: they decreased by the percentage given in Table 7 with BW increasing by $100 \mathrm{~g}$ and GA increasing by 1 week and each subsequent DOL. Moreover, it was shown that the values of this marker were significantly (approx. by 40\%) higher in girls than in boys (Table 7).

Table 4 presents the geometric means and CI50\% for the values of $\mathrm{uOPN}$, broken by gender, that were recorded in the study groups at the 4 time intervals. As it follows from the data and the Jonckheere-Terpstra test results for ordered alternatives, there is no trend of $\mathrm{UOPN}$ values with respect to PNA; however, there is a significant trend of higher $\mathrm{UOPN}$ values correlating with lower BW. The analysis of logarithmic correlations of the uOPN values showed negative, average and high coefficients ( $\mathrm{R}$ : $-0.4--0.7$; Table 6 ) for most of the values with respect to BW and GA. There were no such correlations for the absolute uOPN correlation in girls with respect to GA or $\mathrm{uOPN} / \mathrm{mgCr}$ in boys with respect to $B W$ and GA. In turn, the analysis of the results of the multivariable linear regression for logarithmic uOPN values performed solely with respect to $\mathrm{BW}$ and gender showed a significant effect of these factors (the marker values were significantly higher - by approx. $40 \%$ - in boys than in girls); no significant effect of GA or PNA was observed on the uOPN values (Table 7).

Table 4. Geometric mean and CI50\% of uOPN values calculated from data collected in 4 weekly intervals in the study groups; p-values were computed for the Jonckheere-Terpstra test for ordered alternatives

\begin{tabular}{|c|c|c|c|c|c|}
\hline Variable & 4-7 DOL & 8-14 DOL & 15-21 DOL & $22-28 \mathrm{DOL}$ & $\mathrm{p}$-value \\
\hline \multicolumn{6}{|c|}{ Females } \\
\hline \multicolumn{6}{|c|}{ OPN [ng/mL] } \\
\hline LBW & $79.1(36.8-170.2)$ & $74.4(32.2-172.0)$ & $56.3(19.4-163.3)$ & 76.8 (31.6-186.4) & NS \\
\hline VLBW & $166.6(77.9-356.20)$ & $145.6(57.8-366.3)$ & $109.2(34.1-349.80$ & $164.6(71.1-380.8)$ & NS \\
\hline ELBW & $180.5(99.4-327.8)$ & $139.8(62.8-311.5)$ & $149.6(73.5-304.5)$ & $173.1(56.0-534.8)$ & NS \\
\hline$p$-value & 0.02 & 0.04 & 0.02 & 0.05 & - \\
\hline \multicolumn{6}{|c|}{ OPN [ng/mgCr] } \\
\hline LBW & 493.4 (234.4-1038.4) & $527.3(231.2-1202.6)$ & 478.8 (174.2-1316.3) & $665.4(259.9-1703.7)$ & NS \\
\hline VLBW & $1478.9(699.5-3126.8)$ & $1158.3(469.6-2857.1)$ & 860.3 (297.4-2488.4) & $1377.4(610.4-3108.4)$ & NS \\
\hline ELBW & $1620.4(662.7-3962.2)$ & $1137.3(489.2-2644.2)$ & $1326.6(720.7-2441.7)$ & $1604.6(752.3-3422.7)$ & NS \\
\hline p-value & 0.05 & 0.03 & 0.01 & 0.03 & - \\
\hline \multicolumn{6}{|c|}{ Males } \\
\hline \multicolumn{6}{|c|}{ OPN [ng/mL] } \\
\hline LBW & $126.4(73.8-216.5)$ & 99.1 (44.8-219.3) & $103.9(36.0-299.6)$ & $79.3(19.5-323.3)$ & NS \\
\hline VLBW & $227.1(99.5-518.3)$ & $134.8(58.1-312.5)$ & $127.6(65.4-248.8)$ & $183.9(100.4-336.7)$ & NS \\
\hline ELBW & $244.4(104.2-573.1)$ & $250.4(114.3-548.6)$ & $290.9(130.5-648.3)$ & $244.5(107.0-558.5)$ & NS \\
\hline$p$-value & 0.05 & 0.01 & 0.02 & 0.01 & - \\
\hline \multicolumn{6}{|c|}{ OPN [ng/mgCr] } \\
\hline LBW & $897.7(518.9-1553.1)$ & 764.8 (366.9-1593.8) & $614.2(212.3-1776.7)$ & $581.7(167.6-2018.6)$ & NS \\
\hline VLBW & $1754.8(787.8-3908.8)$ & $1223.6(524.1-2856.5)$ & $1159.0(621.5-2161.5)$ & $1641.9(976.0-2762.2)$ & NS \\
\hline ELBW & $2274.4(1115.5-4637.4)$ & $1815.2(956.4-3445.1)$ & $2611.5(1087.5-6271.6)$ & 2260.8 (983.9-5194.7) & NS \\
\hline$p$-value & 0.01 & 0.01 & 0.01 & 0.003 & - \\
\hline
\end{tabular}

DOL - days of life; LBW - low body weight; VLBW - very low body weight; ELBW - extremely low body weight; OPN - osteopontin; uOPN - urine osteopontin. 
Table 5. Geometric mean and CI50\% of hKIM1 values calculated from data collected in 4 weekly intervals in the study groups; p-values were computed for the Jonckheere-Terpstra test for ordered alternatives

\begin{tabular}{|c|c|c|c|c|c|}
\hline Variable & 4-7 DOL & 8-14 DOL & 15-21 DOL & 22-28 DOL & $p$-value \\
\hline \multicolumn{6}{|c|}{ Females } \\
\hline \multicolumn{6}{|c|}{ hKIM1 [pg/mL] } \\
\hline LBW & 74.6 (41.9-132.6) & $130.4(73.1-232.7)$ & $88.8(43.8-180.0)$ & $69.6(33.3-145.4)$ & NS \\
\hline VLBW & 73.6 (39.1-138.6) & $84.3(41.6-170.7)$ & $112.4(59.8-211.1)$ & $115.3(58.0-229.0)$ & 0.05 \\
\hline ELBW & $74.9(23.9-234.5)$ & $90.3(41.3-197.6)$ & $173.6(92.8-324.5)$ & $160.0(71.6-357.5)$ & NS \\
\hline$p$-value & NS & NS & 0.02 & 0.05 & - \\
\hline \multicolumn{6}{|c|}{ hKIM1 [pg/mgCr] } \\
\hline LBW & $471.0(279.0-795.1)$ & 882.5 (489.8-1590.3) & 658.7 (367.5-1180.7) & $613.8(337.1-1117.7)$ & NS \\
\hline VLBW & $679.0(358.8-1285.0)$ & 692.8 (325.2-1476.1) & 912.9 (489.7-1701.7) & 964.0 (466.6-1991.6) & 0.05 \\
\hline ELBW & 776.9 (186.9-3230.1) & 774.5 (311.0-1928.7) & 1347.5 (704.1-2578.8) & $1124.2(562.6-2246.4)$ & NS \\
\hline p-value & NS & NS & 0.01 & 0.03 & - \\
\hline \multicolumn{6}{|c|}{ Males } \\
\hline \multicolumn{6}{|c|}{ hKIM1 [pg/mL] } \\
\hline LBW & 75.5 (32.9-173.3) & $126.7(60.7-264.4)$ & $113.6(59.1-218.6)$ & $89.7(49.3-163.4)$ & NS \\
\hline VLBW & $88.6(42.7-183.5)$ & $91.4(46.3-180.3)$ & $167.8(92.2-305.3)$ & $115.6(59.0-226.7)$ & NS \\
\hline ELBW & $82.5(41.1-165.8)$ & $254.6(166.0-390.4)$ & $252.0(151.3-419.8)$ & $161.1(80.5-322.4)$ & NS \\
\hline$p$-value & NS & NS & 0.02 & 0.01 & - \\
\hline \multicolumn{6}{|c|}{ hKIM1 [pg/mgCr] } \\
\hline LBW & 513.0 (230.7-1141.0) & 995.7 (481.4-2059.1) & $815.8(402.8-1652.6)$ & 619.1 (342.9-1117.9) & NS \\
\hline VLBW & 710.4 (321.6-1569.1) & $802.6(403.4-1596.7)$ & 1536.3 (852.8-2767.7) & 1031.0 (572.3-1857.4) & NS \\
\hline ELBW & 719.7 (354.6-1460.9) & $1862.4(1215.6-2853.2)$ & $2369.4(1338.3-4194.9)$ & $1390.4(743.3-2600.5)$ & NS \\
\hline$p$-value & NS & NS & 0.01 & 0.03 & - \\
\hline
\end{tabular}

DOL - days of life; LBW - low body weight; VLBW - very low body weight; ELBW - extremely low body weight; hKIM1 - human kidney injury molecule 1.

Table 6. Pearson correlation coefficients ( $p$-value) for the mean values of the investigated urine tubular biomarkers calculated for each patient from 4 to 28 DOL with reference to BW and GA and between the log-norm and PNA values

\begin{tabular}{|c|c|c|c|}
\hline Biomarker & BW vs mean (log $10($ marker $))$ & GA vs mean (log $\log _{10}($ marker $\left.)\right)$ & DOL vs $\log _{10}($ marker $)$ \\
\hline \multicolumn{4}{|c|}{ Female } \\
\hline $\mathrm{NGAL}[\mathrm{ng} / \mathrm{mL}]$ & $-0.453(0.012)$ & $-0.403(0.027)$ & $-0.103(0.011)$ \\
\hline $\mathrm{NGAL}[\mathrm{ng} / \mathrm{mgCr}]$ & $-0.484(0.007)$ & $-0.398(0.029)$ & $-0.086(0.033)$ \\
\hline \multicolumn{4}{|c|}{ Male } \\
\hline $\mathrm{NGAL}[\mathrm{ng} / \mathrm{mL}]$ & $-0.609(0.000)$ & $-0.619(0.000)$ & $-0.198(0.000)$ \\
\hline $\mathrm{NGAL}[\mathrm{ng} / \mathrm{mgCr}]$ & $-0.437(0.016)$ & $-0.472(0.008)$ & $-0.181(0.000)$ \\
\hline \multicolumn{4}{|c|}{ Female } \\
\hline OPN [ng/mL] & $-0.385(0.036)$ & -0.327 (NS) & -0.021 (NS) \\
\hline OPN [ng/mgCr] & $-0.477(0.008)$ & $-0.391(0.032)$ & 0.002 (NS) \\
\hline \multicolumn{4}{|c|}{ Male } \\
\hline OPN $[n g / m L]$ & $-0.514(0.004)$ & $-0.414(0.023)$ & -0.005 (NS) \\
\hline OPN [ng/mgCr] & -0.130 (NS) & -0.100 (NS) & 0.030 (NS) \\
\hline \multicolumn{4}{|c|}{ Female } \\
\hline hKIM1 [pg/mL] & -0.152 (NS) & -0.171 (NS) & $0.131(0.002)$ \\
\hline hKIM1 [pg/mgCr] & -0.270 (NS) & -0.238 (NS) & $0.130(0.002)$ \\
\hline \multicolumn{4}{|c|}{ Male } \\
\hline hKIM1 [pg/mL] & -0.084 (NS) & -0.045 (NS) & $0.118(0.009)$ \\
\hline hKIM1 [pg/mgCr] & 0.150 (NS) & 0.128 (NS) & $0.151(0.001)$ \\
\hline
\end{tabular}

BW - body weight; GA - gestational age; PNA - postnatal age; NGAL - neutrophil gelatinase-associated lipocalin; OPN - osteopontin; hKIM1 - human kidney injury molecule 1. 
Table 7. Multivariable linear regression for the log-norm data in reference to BW, GA, PNA, and gender. The table presents the change (increase/decrease) by a given percent of the marker expressed in the original values when the given parameter is changed by a set point value (negative values denote a decrease in the marker value at an increase of the given parameter)

\begin{tabular}{|c|c|c|c|c|}
\hline Variable & $\mathrm{BW}[100 \mathrm{~g}]$ & GA [week] & DOL [day] & $\mathrm{G}$ (from female to male) \\
\hline $\begin{array}{l}\text { NGAL }[\mathrm{ng} / \mathrm{mL}] \\
\text { p-value }\end{array}$ & $\begin{array}{c}-11.2(95 \% \mathrm{Cl}=-14.4--7.9) \\
<0.001\end{array}$ & $\begin{array}{c}-10.7(95 \% \mathrm{Cl}=-14.7--6.6) \\
<0.001\end{array}$ & $\begin{array}{c}-4.5(95 \% \mathrm{Cl}=-5.6--3.3) \\
<0.001\end{array}$ & $\begin{array}{c}-38.4(95 \% \mathrm{Cl}=-47.9--27.2) \\
<0.001\end{array}$ \\
\hline $\begin{array}{l}\text { NGAL }[\mathrm{ng} / \mathrm{mgCr}] \\
\mathrm{p} \text {-value }\end{array}$ & $\begin{aligned}-13.4(95 \% & \mathrm{Cl}=-16.6--10.1) \\
& <0.001\end{aligned}$ & $\begin{array}{c}-11.3(95 \% \mathrm{Cl}=-15.3--7.1) \\
<0.001\end{array}$ & $\begin{array}{c}-4.4(95 \% \mathrm{Cl}=-5.6--3.2) \\
<0.001\end{array}$ & $\begin{aligned}-37.8(95 \% \mathrm{Cl} & =-47.7--26.2) \\
& <0.001\end{aligned}$ \\
\hline $\begin{array}{l}\text { OPN }[\mathrm{ng} / \mathrm{mL}] \\
\mathrm{p} \text {-value }\end{array}$ & $\begin{array}{c}-8.6(95 \% \mathrm{Cl}=-11.9--5.1) \\
<0.001\end{array}$ & $\begin{array}{c}-1.5(95 \% \mathrm{Cl}=-5.9-3.1) \\
\text { NS }\end{array}$ & $\begin{array}{c}-0.8(95 \% \mathrm{Cl}=-1.9-0.4) \\
\text { NS }\end{array}$ & $\begin{array}{c}39.2(95 \% \mathrm{Cl}=17.7-64.8) \\
<0.001\end{array}$ \\
\hline $\begin{array}{l}\text { OPN }[\mathrm{ng} / \mathrm{mgCr}] \\
\text { p-value }\end{array}$ & $\begin{array}{c}-10.4(95 \% \mathrm{Cl}=-13.5--7.2) \\
<0.001\end{array}$ & $\begin{array}{c}-2.2(95 \% \mathrm{Cl}=-6.4-2.2) \\
\mathrm{NS}\end{array}$ & $\begin{array}{c}-0.4(95 \% \mathrm{Cl}=-1.5-0.8) \\
\text { NS }\end{array}$ & $\begin{array}{c}43.2(95 \% \mathrm{Cl}=22.0-68.1) \\
<0.001\end{array}$ \\
\hline $\begin{array}{l}\text { hKIM1 }[\mathrm{ng} / \mathrm{mL}] \\
\text { p-value }\end{array}$ & $\begin{array}{c}-1.2(95 \% \mathrm{Cl}=-4.0-1.7) \\
0.415(\mathrm{NS})\end{array}$ & $\begin{array}{c}-0.6(95 \% \mathrm{Cl}=-4.2-3.0) \\
\text { NS }\end{array}$ & $\begin{array}{c}1.8(95 \% \mathrm{Cl}=0.9-2.7) \\
<0.001\end{array}$ & $\begin{array}{c}24.6(95 \% \mathrm{Cl}=9.5-41.7) \\
<0.001\end{array}$ \\
\hline $\begin{array}{l}\text { hKIM1 }[\mathrm{ng} / \mathrm{mgCr}] \\
\text { p-value }\end{array}$ & $\begin{array}{c}-2.8(95 \% \mathrm{Cl}=-5.6-0.1) \\
0.056(\mathrm{NS})\end{array}$ & $\begin{array}{c}-1.7(95 \% \mathrm{Cl}=-5.2-2.0) \\
\text { NS }\end{array}$ & $\begin{array}{c}1.9(95 \% \mathrm{Cl}=1.0-2.8) \\
<0.001\end{array}$ & $\begin{array}{c}29.9(95 \% \mathrm{Cl}=14.1-48.0) \\
<0.001\end{array}$ \\
\hline
\end{tabular}

BW - body weight; GA - gestational age; PNA - postnatal age; NGAL - neutrophil gelatinase-associated lipocalin; OPN - osteopontin; hKIM1 - human kidney injury molecule 1; $G$ - gender.

Table 5 presents the geometric means and CI50\% for the values of hKIM1 by gender for the 4 time intervals in the groups of children studied. As it follows from the data and the Jonckheere-Terpstra test results for ordered alternatives, there is no trend of hKIM1 values with respect to PNA (except VLBW females); there is, however, a significant trend of higher hKIM1 values and lower BW, but only at the $3^{\text {rd }}$ and $4^{\text {th }}$ time intervals. The analysis of correlation coefficients of the logarithmic hKIM1 values did not demonstrate any correlations with BW, GA or PNA (Table 6); similarly, the multivariable linear regression performed for logarithmic marker values did not show BW or GA to exert a significant effect on the hKIM1 values; only in terms of PNA and gender did the regression demonstrate a significant effect of these factors on the marker values, as hKIM1 values were significantly (25-30\%) higher in boys than in girls (Table 7).

\section{Discussion}

There are many urinary markers which are detectable in neonates, but in this heterogeneous population no clear neonatal reference ranges have been developed. Therefore, one of the main objectives of this study was to define appropriate values of UNGAL, uOPN and hKIM1 recorded in LBW, VLBW and ELBW infants with uncomplicated clinical course and with normal kidney function. Moreover, the majority of studies of modern AKI markers only include special neonatal populations, such as newborns presenting with post-neonatal asphyxia ${ }^{28}$ or requiring cardiac surgery. ${ }^{29}$

Studies dedicated to AKI biomarkers in healthy preterm and term neonates are not only very scarce, but the results of such studies are also highly diverse and sometimes quite conflicting. ${ }^{30}$ To illustrate this fact, it should be mentioned that there are reports where the UNGAL values are quite comparable with the results obtained in the current study, ${ }^{17,25,30,31}$ while in other studies, ${ }^{2,10,23,32-34}$ the values of uNGAL (and uNGAL/mgCr ${ }^{10,20,33}$ ) are higher than in this study. In turn, in the study by Askenazi et al., ${ }^{34}$ the values of $\mathrm{UOPN}$ are comparable, yet in a report published 5 years later by the same author, the values of uOPN and $\mathrm{uOPN} / \mathrm{mgCr}$ are higher than in the current study. ${ }^{33}$ Finally, in the studies by Askenazi et al. ${ }^{10,34}$ and Genc et al. ${ }^{35}$ addressing the hKIM1 and hKIM1/mgCr levels in preterm neonates, the values of these biomarkers are comparable to those found in this study, but there are also reports which published higher values. ${ }^{36,37}$ Only in 1 study concerning term infants were the hKIM1 and hKIM1/mgCr values lower than the values found in the present study. ${ }^{31}$ The causes of such disparities can mainly be found in the days of life in which the urine samples were collected from the newborns for measuring particular biomarkers. Only in some studies (by La Manna et al., ${ }^{2}$ Huynh et al., ${ }^{17}$ Parravicini et al., ${ }^{25}$ and Chi-Nien et al). ${ }^{23}$ were the days of urine collection similar to the timespan used in the present study, and they included practically the entire neonatal period. In the remaining studies, the concentration values of the given biomarkers were determined within a much shorter timeframe - most often in the very first 7 days of life. . $^{10,31-33,35-37}$

Analyzing the importance and effect of gender on the values of the markers under discussion, one realizes that data from the subject literature are fairly scarce and ambiguous. There are reports stating that there is a higher level and increased variability of uNGAL in girls, ${ }^{17}$ as well as other papers claiming that there is no significant association with gender. ${ }^{23,25,30}$ The available literature is quite unambiguous in stating that there is no correlation and no effect of gender on the values of hKIM1. ${ }^{35-37}$ In the present study, gender exerts a highly significant effect of several score percent on the values of the 3 investigated tubular markers. 
Moreover, in the current literature there are various - sometimes discrepant - reports concerning the effect of GA, BW and PNA on the concentations of the urinary renal markers in question. According to a number of studies, uNGAL is inversely correlated with $\mathrm{GA}^{1,10,17,38}$; additionally, inverse correlations with $\mathrm{BW}^{38}$ and PNA have been demonstrated. ${ }^{17}$ Furthermore, according to Askenazi et al., ${ }^{10}$ uNGAL/mgCr also decreases with increasing GA, and there are detailed reports where UNGAL levels declined by $23.1 \%{ }^{10}$ or by $17.8 \%{ }^{17}$ for each week of increasing GA. However, there are also researchers who found no association between $\mathrm{UNGAL}$ and $\mathrm{GA}^{23,25,30,39}$ and those who report no correlation with BW, ${ }^{23,30,39}$ or PNA. ${ }^{23,27,38}$ However, Huynh et al. ${ }^{17}$ demonstrated that uNGAL levels declined by $1.33 \%$ for each day of PNA. In the present study, all of the UNGAL values in both genders were highly inversely correlated with BW and GA. Furthermore, statistically significant decreasing trends of UNGAL with respect to PNA and increasing trends with respect to lower BW were found. Moreover, in the linear regression, the above factors exerted a significant effect on $\mathrm{UNGAL}$ values, as did PNA. Gender also plays a significant role, since the values of uNGAL in girls were significantly higher.

Reports concerning correlations with uOPN are quite scarce, as only Askenazi et al. ${ }^{10}$ showed that $\mathrm{uOPN} / \mathrm{mgCr}$ decreased with increasing GA and that $\mathrm{UOPN}$ declined by $34.8 \%$ for each week of increasing GA. In the present study, most of the uOPN values were inversely correlated with BW and GA (which was also confirmed by a statistically significant increasing trend of $\mathrm{uOPN}$ values with respect to lower BW); nevertheless, an increase of GA by 1 week (similarly as is the case with PNA) did not exert a significant effect on the values of the marker when it was analyzed using linear regression. On the other hand, gender played a significant role, since the uOPN values in boys were significantly higher.

In the study by Askenazi et al., ${ }^{10} \mathrm{hKIM} 1$ and hKIM1/mgCr were shown to decrease with increasing GA. The same correlation concerning only hKIM1 was found by Sarafidis et al., ${ }^{31}$ but this study was performed in term infants. Nevertheless, there are studies which proved no correlation between hKIM1 and GA ${ }^{35,36}$; likewise, BW has been reported not to correlate with this marker. ${ }^{35,37}$ On the other hand, in a study that was performed in a population of term infants, GA correlated positively with hKIM1. ${ }^{37}$ The present study did not demonstrate any correlation between hKIM1 and BW or GA (only in the $3^{\text {rd }}$ and $4^{\text {th }}$ time intervals is there a statistically significant inverse correlation between hKIM1 and BW). Postnatal age exerted a weak effect and gender had a significant effect on the marker value in the linear regression, since the hKIM1 values in boys were significantly higher.

Glomerular filtration rate in term (and particularly in preterm) infants is very low, and there is a wide distribution of normal SCr values, which vary greatly depending on the level of prematurity and PNA. ${ }^{40}$ Depending on the degree of the neonate's prematurity, GFR steadily improves during the first months of life. Keeping this observation in mind, we additionally measured the ranges of $\mathrm{SCr}$ values and calculated eGFR values in the $3 \mathrm{BW}$ groups of neonates with normal kidney function between 4 and 28 DOL.

We are aware of some limitations of this study, including the fact that the number of neonates - particularly in the ELBW group - is relatively small, but this issue stems from the considerable difficulty in forming a study group consisting of numerous, homogeneous and unquestionably healthy neonates without comorbidities. Nevertheless, a high number of days (214) in the analyzed ELBW children made the authors inclined to treat this group as a separate entity. Furthermore, analyzing the diagnoses (mostly prematurity and respiratory disorders), MAP values and SNAP scale, it may be concluded that the entire study population was in generally good clinical condition. Additionally, the confounding factors (AG) were also acknowledged in the statistical calculations.

The main advantage of the current study was its scrupulous collection of serum samples (every 48-72 h) for $\mathrm{SCr}$, as well as urine samples (every $24 \mathrm{~h}$ ) for urinary renal markers throughout the neonatal period in the LBW, VLBW and ELBW infants with normal kidney function, which allowed for a detailed background to define reference weekly ranges for SCr, eGFR and 3 AKI urinary tubular markers. Also, to minimize the variability related to urinary concentration, the correction with urine creatinine was adopted. However, due to the limited number of patients included in the study, there is a future need for validation and evaluation of the above data in larger groups of neonates to provide the most reliable reference values, ideally in multicenter studies.

In summary, the findings of this study demonstrate that tubular and glomerular function in preterm neonates during the $1^{\text {st }}$ month of life is significantly affected by BW, GA and PNA. Furthermore, gender also exerts a significant effect on the values of the markers studied: the uNGAL values are significantly higher in girls, while $\mathrm{UOPN}$ and hKIM1 are higher in boys. Secondly, we determined the values of 3 urine tubular biomarkers (uNGAL, uOPN and hKIM1) recorded in a substantially healthy, preterm population of neonates with normal kidney function, along with any trends of these values with respect to PNA and BW, which should form a solid groundwork for rational interpretation of the results of future clinical trials using the same AKI biomarkers in very young children.

\section{ORCID iDs}

Monika Miklaszewska (D) https://orcid.org/0000-0003-0776-4946 Przemysław Korohoda (D) https://orcid.org/0000-0002-8768-012X Dorota Drożdż (1) https://orcid.org/0000-0002-1281-1164 Katarzyna Zachwieja (D) https://orcid.org/0000-0002-1949-5096 Tomasz Tomasik (D) https://orcid.org/0000-0003-2107-3607 Anna Moczulska (D) https://orcid.org/0000-0002-8479-050X Agata Korzeniecka-Kozerska (i) https://orcid.org/0000-0001-6165-3302 Przemko Kwinta (D) https://orcid.org/0000-0002-3017-0348 


\section{References}

1. Gubhaju L, Sutherland MR, Horne R, et al. Assessment of renal functional maturation and injury in preterm neonates during the first month of life. Am J Physiol Renal Physiol. 2014;307(2):F149-F158.

2. La Manna G, Galletti S, Capelli I, et al. Urinary neutrophil gelatinaseassociated lipocalin at birth predicts early renal function in very low birth weight infants. Pediatr Res. 2011;70(4):379-383.

3. Koralkar R, Ambalavanan N, Levitan EB, McGwin G, Goldstein S, Askenazi $D$. Acute kidney injury reduces survival in very low birth weight infants. Pediatr Res. 2011;69(4):354-358.

4. Jetton JG, Askenazi DJ. Update on acute kidney injury in the neonate. Curr Opin Pediatr. 2012;24(2):191-196.

5. Stojanović VD, Barišić NA, Vučković NM, Doronjski AD, Peco Antić AE. Urinary kidney injury molecule-1 rapid test predicts acute kidney injury in extremely low-birth-weight neonates. Pediatr Res. 2015; 78(4):430-435

6. Akcan-Arikan A, Zappitelli M, Loftis LL, Washburn KK, Jefferson LS, Goldstein SL. Modified RIFLE criteria in critically ill children with acute kidney injury. Kidney Int. 2007;71(10):1028-1035.

7. Abitbol CL, Bauer CR, Montané B, Chandar J, Duara S, Zilleruelo G. Longterm follow-up of extremely low birth weight infants with neonatal renal failure. Pediatr Nephrol. 2003;18(9):887-893.

8. Libório AB, Pereira Castello Branco KM, Torres deMelo Bezerra C. Acute kidney injury in neonates: From urine output to new biomarkers. BioMed Res Int. 2014;2014:601568.

9. Greenberg JH, Parikh CR. Biomarkers for diagnosis and prognosis of AKI in children: One size does not fit all. Clin J Am Soc Nephrol. 2017;12(9):1551-1557.

10. Askenazi DJ, Koralkar R, Levitan EB, et al. Baseline values of candidate urine acute kidney injury biomarkers vary by gestational age in premature infants. Pediatr Res. 2011;70(3):302-306.

11. Mishra J, Ma Q, Prada A, et al. Identification of neutrophil gelatinaseassociated lipocalin as a novel early urinary biomarker for ischemic renal injury. J Am Soc Nephrol. 2003;14(10):2534-2543.

12. Han WK, Bailly V, Abichandani R, Thadhani R, Bonventre JV. Kidney injury molecule-1 (KIM-1): A novel biomarker for human renal proximal tubule injury. Kidney Int. 2002;62(1):237-244.

13. Liangos $\mathrm{O}$, Perianayagam MC, Vaidya VS, et al. Urinary N-acetyl-beta(D)-glucosaminidase activity and kidney injury molecule-1 level are associated with adverse outcomes in acute renal failure. J Am Soc Nephrol. 2007;18(3):904-912.

14. Trof RJ, Di Maggio F, Leemreis J, Groeneveld AB. Biomarkers of acute renal injury and renal failure. Shock. 2006;26(3):245-253.

15. Nguyen MT, Devarajan P. Biomarkers for the early detection of acute kidney injury. Pediatr Nephrol. 2008;23(12):2151-2157.

16. Mori K, Lee HT, Rapoport D, et al. Endocytic delivery of lipocalin-siderophore-iron complex rescues the kidney from ischemia-reperfusion injury. J Clin Invest. 2005;115(3):610-621.

17. Huynh TK, Bateman DA, Parravicini E, et al. Reference values of urinary neutrophil gelatinase-associated lipocalin in very low birth weight infants. Pediatr Res. 2009;66(5):528-532.

18. Xie Y, Sakatsume M, Nishi S, Narita I, Arakawa M, Gejyo F. Expression, roles, receptors, and regulation of osteopontin in the kidney. Kidney Int. 2001;60(5):1645-1657.

19. Bailly V, Zhang Z, Meier W, Cate R, Sanicola M, Bonventre JV. Shedding of kidney injury molecule-1, a putative adhesion protein involved in renal regeneration. J Biol Chem. 2002;277(42):39739-39748.

20. Coca SG, Yalavarthy R, Concato J, Parikh CR. Biomarkers for the diagnosis and risk stratification of acute kidney injury: A systematic review. Kidney Int. 2008;73(9):1008-1016.
21. Thongboonkerd V, Malasit P. Renal and urinary proteomics: Current applications and challenges. Proteomics. 2005;5(4):1033-1042.

22. Schwartz GJ, Munoz A, Schneider MF, et al. New equations to estimate GFR in children with CKD. J Am Soc Nephrol. 2009;20(3):629-637.

23. Chi-Nien C, Chia-Hung C, Suh-Fang J, et al. Urinary neutrophil gelatinase-associated lipocalin levels in neonates. Pediatr Neonatol. 2016; 57(33):207-212.

24. Bateman DA, Thomas W, Parravicini E, Polesana E, Locatelli C, LorenzJM. Serum creatinine concentration in very-low-birth-weight infants from birth to 34-36 week postmenstrual age. Pediatr Res. 2015;77(5): 696-702

25. Parravicini E, Lorenz JM, Nemerofsky SL, O'Rourke M, Barasch J, Bateman D. Reference range of urinary neutrophil gelatinase-associated lipocalin in very low-birth-weight infants: Preliminary data. Am J Perinatol. 2009;26(6):437-440.

26. Noemi M, Ramirez M, Godoy LE, Barrientos EA. SNAP II and SNAPPE II as predictors of neonatal mortality in a pediatric intensive care unit: Does postnatal age play a role? Int J Pediatr. 2014;2014:298198.

27. Dionne JM, Abitbol CL, Flynn JT. Hypertension in infancy: Diagnosis, management and outcome. Pediatr Nephrol. 2012;27(1):17-32.

28. Selewski DT, Jordan BK, Askenazi DJ, Dechert RE, Sarkar S. Acute kidney injury in asphyxiated newborns treated with therapeutic hypothermia. J Pediatr. 2013;162(4):725-729.

29. Alabbas A, Campbell A, Skippen P, Human D, Matsell D, Mammen C. Epidemiology of cardiac surgery-associated acute kidney injury in neonates: A retrospective study. Pediatr Nephrol. 2013;28(7):1127-1134.

30. Elmas AT, Tabel Y, Ipek S. Determination of reference values for urinary neutrophil gelatinase-associated lipocalin in premature infants. J Matern Fetal Neonatal Med. 2014;27(2):187-191.

31. Sarafidis K, Tsepkentzi E, Agakidou E, et al. Serum and urine acute kidney injury biomarkers in asphyxiated neonates. Pediatr Nephrol, 2012;27(9):1575-1582.

32. Cangemi G, Storti S, Cantinotti M, et al. Reference values for urinary neutrophil gelatinase-associated lipocalin (NGAL) in pediatric age measured with a fully automated chemiluminescent platform. Clin Chem Lab Med. 2013;51(5):1101-1105.

33. Askenazi DJ, Koralkar R, Patil N, Halloran B, Ambalavanan N, Griffin R. Acute kidney injury urine biomarkers in very low-birth-weight infants. Clin J Am Soc Nephrol. 2016;11(9):1527-1535.

34. Askenazi DJ, Montesanti $\mathrm{A}$, Hunley $\mathrm{H}$, et al. Urine biomarkers predict acute kidney injury and mortality in very low birth weight infants. J Pediatr. 2011;159(6):907-912.

35. Genc G, Ozkaya O, Avci B, Aygun C, Kucukoduk. Kidney injury molecule-1 as a promising biomarker for acute kidney injury in premature babies. Am J Perinatol. 2013;30(3):245-252.

36. Youssef M, Abdelsalam M, Saeed R, Mohamed A. Urinary kidney injury molocule-1 level in preterm neonates with respiratory distress syndrome. Open J Pediatr. 2016;6(1):1-9.

37. Kamianowska M, Szczepański M, KulikowskaEE, Bebko B, Wasilewska A. Do serum and urinary concentrations of kidney injury molecule-1 in healthy newborns depend on birth weight, gestational age or gender? J Perinatol. 2017;37(1):73-76.

38. Lavery AP, Meinzen-Derr JK, Anderson E, et al. Urinary NGAL in premature infants. Pediatr Res. 2008;64(4):423-428.

39. Suchojad A, Tarko A, Smertka M, et al. Factors limiting usefulness of serum and urinary NGAL as a marker of acute kidney injury in preterm newborns. Ren Fail. 2015;37(3):439-445.

40. Aggarwal A, Kumar P, Chowdhary G, Majumdar S, Narang A. Evaluation of renal functions in asphyxiated newborns. J Trop Pediatr. 2005; 51(5):295-299. 